\title{
Técnicas del metal, artesanos y talleres en las sociedades antiguas: de la edad del Bronce final al periodo romano en la Europa occidental
}

Techniques du métal, artisans et ateliers dans les sociétés antiques : de l'âge du Bronze final à l'époque romaine en Europe occidentale

Metal techniques, craftsmen and workshops: from Late Bronze Age to the roman period in Western Europe

\section{Michel Pernot}

\section{OpenEdition}

Journals

Edición electrónica

URL: http://journals.openedition.org/bifea/1966

DOI: $10.4000 /$ bifea. 1966

ISSN: 2076-5827

Editor

Institut Français d'Études Andines

Edición impresa

Fecha de publicación: 1 agosto 2010

Paginación: 331-350

ISSN: 0303-7495

Referencia electrónica

Michel Pernot, «Técnicas del metal, artesanos y talleres en las sociedades antiguas: de la edad del Bronce final al periodo romano en la Europa occidental », Bulletin de l'Institut français d'études andines [En línea], 39 (2) | 2010, Publicado el 01 febrero 2011, consultado el 10 diciembre 2020. URL : http:// journals.openedition.org/bifea/1966 ; DOI : https://doi.org/10.4000/bifea.1966

\section{cc) (†) $\odot$}

Les contenus du Bulletin de l'Institut français d'études andines sont mis à disposition selon les termes de la licence Creative Commons Attribution - Pas d'Utilisation Commerciale - Pas de Modification 4.0 International. 


\title{
Técnicas del metal, artesanos y talleres en las sociedades antiguas: de la edad del Bronce final al periodo romano en la Europa occidental
}

\author{
Michel Pernot*
}

\section{Resumen}

La ciencia de los materiales ayuda hoy en día a caracterizar las aleaciones y los procesos de fabricación empleados por los artesanos. Además del estudio de objetos acabados, la excavación de talleres permite descubrir desechos, caídas de trabajo, subproductos y fallas de fabricación, así como estructuras de construcciones y vestigios relacionados con la organización de los talleres. Se exponen unos resultados obtenidos con esta metodología, en el área geográfica de Europa occidental, de la edad del Bronce final al periodo romano.

Palabras clave: objeto metálico, metal, aleación, proceso de fabricación, artesano, taller, ciencia de los materiales, excavación arqueológica, edad del Bronce, periodo romano, Europa occidental

\section{Techniques du métal, artisans et ateliers dans les sociétés antiques : de l'âge du Bronze final à l'époque romaine en Europe occidentale}

\section{Résumé}

La science des matériaux aide de nos jours à caractériser les alliages et les procédés de mise en forme employés par les artisans. En plus des objets finis, la fouille de sites de fabrication permet de découvrir

* IRAMAT-UMR 5060, CNRS-Université Bordeaux 3, Maison de l'archéologie - 33607 Pessac Cedex

- France. E-mail: mpernot@u-bordeaux3.fr 
des déchets, des chutes de travail, des sous-produits et des ratés de fabrication, ainsi que des structures de bâtiments et des vestiges d'ateliers. Des résultats obtenus par cette méthodologie dans le domaine géographique de l'Europe occidentale sont présents ici, allant de l'âge du Bronze final à la période romaine.

Mots clés : objet métallique, métal, alliage, procédé de fabrication, artisan, atelier, science des matériaux, fouille archéologique, âge du Bronze, période romaine, Europe occidentale

\title{
Metal techniques, craftsmen and workshops: from Late Bronze Age to the roman period in Western Europe
}

\begin{abstract}
Alloys and shaping processes used by ancient craftsmen can be characterized with the help of materials science. The excavation of workshops allows the discovery, not only of finished objects, but also of wasters, scraps, under-products and unfinished artifacts, and of remains of the buildings and of the spatial organization of work. Examples of the results obtained with this methodology are given for the Late Bronze Age and the Roman period in Western Europe.
\end{abstract}

Key-words: metallic artifact, metal, alloy, shaping process, craftsman, workshop, materials science, archaeological excavation, Bronze Age, Roman period, Western Europe

\section{LA ARQUEOLOGÍA DEL METAL}

Los objetivos de la temática son, en primer lugar, dar a conocer de manera precisa, características técnicas de las prácticas de los artesanos que fabrican objetos metálicos, para luego poder reconstituir cadenas operativas y establecer cómo estas determinan sus estilos de vida y maneras de pensar. Los aspectos técnicos abarcan principalmente la elección de las aleaciones —los metales siendo ya previamente elaborados-y los procesos empleados para la fabricación de cada pieza con sus respectivas herramientas asociadas. Esto está relacionado con los vestigios materiales (moldes, crisoles, martillos, etc.) pero también con bienes muebles tales como hornos, fosas, yunques fijos para la deformación; y finalmente, con el taller en el cual se lleva a cabo la fabricación.

En términos arqueológicos se trata, entonces, a partir de los vestigios conservados, de estudiar las estructuras y también los vestigios vinculados a las actividades de fabricación para entender el funcionamiento del taller y su organización espacial. Es necesario interesarse por todos los vestigios procedentes de las actividades artesanales, lo cual implica tomar en cuenta otros materiales, además del metal, como rocas, arcillas, arena, madera, cuero, etc. Más allá, son los aspectos sociales que deseamos reconstituir. Intercambios de materiales, objetos, conocimientos e individuos intervienen obligatoriamente en las acciones de producción que 
se desarrollan en un contexto económico, el cual, queda aún por definir. La funcionalidad de los artefactos no siempre es fácil de interpretar; por ejemplo, los objetos de metal producidos para un uso monetario, o pre monetario, dependen de elecciones específicas cuyos motivos son a veces difíciles de percibir. Entre los aspectos sociales, intentamos comprender la organización del mundo de los artesanos. ¿Están agrupados en una corporación vinculada al oficio y dotada de cierto poder?, o más bien ¿Son totalmente dependientes de una elite que dirige, más específicamente la vida política y/o religiosa? La cuestión de las modalidades de transmisión de los conocimientos es también muy importante. Naturalmente, el aprendizaje constituye el medio esencial, pero se debe asimismo examinar el modo de contratación de los aprendices, el cual puede estar muy vinculado a los lazos familiares. Evidentemente, el estudio arqueológico aporta pocos elementos de respuesta a estos interrogantes porque se inscriben más en el ámbito social. Sin embargo, el tamaño de los talleres, su eventual especialización y su posible agrupamiento en barrios son argumentos indirectos que deben ser considerados (Chardron-Picault \& Pernot, 1999: 195-201).

Una técnica puede ser descrita por una cadena operativa; esta asocia materiales y herramientas a usos y conocimientos. Nótese que los materiales y las herramientas forman parte de la cultura material porque constituyen, en algunos casos, vestigios arqueológicos, mientras que los gestos y conocimientos, que se asocian a la parte inmaterial de una «cultura técnica», solo son accesibles de manera indirecta.

\section{1. El metal es reciclable}

Una consecuencia, propia de los materiales metálicos, es el reciclado. Esta tiene que ser enfatizada porque tendrá consecuencias al nivel de las interpretaciones arqueológicas. Los metales y aleaciones no ferrosos empleados por las culturas antiguas, es decir, las aleaciones en base a cobre, las aleaciones preciosas (en base a oro o plata) así como el plomo, el estaño y las mezclas de estos dos últimos metales, se funden facilmente porque la temperatura máxima que se debe lograr no sobrepasa los $1100^{\circ} \mathrm{C}$. Todo trabajo de metal, que sea en fundición o deformación plástica, genera desechos o caídas de metal (canales de alimentación, recortes de láminas, etc.) y fallas de fabricación. Teniendo en cuenta el valor de estos materiales, estos son lógicamente refundidos, es decir, reciclados; lo mismo pasa generalmente con los objetos fuera de uso o de «moda». En consecuencia, los resultados arqueológicos, evidentes pero que no deben dejarse de lado, son que todo lo que es reciclado ya no existe y que siempre hay que tomar en cuenta la posibilidad de mezclas de metales y aleaciones. Eso explica que solamente una reducida parte del metal que estuvo en circulación en el pasado llega al arqueólogo; y la proporción — siempre baja - de lo que escapa al reciclado es generalmente imposible de estimar. Los objetos que subsisten son el resultado de un accidente o de un acto social deliberado. Los accidentes más usuales son la simple pérdida del objeto, los naufragios de barcos y las catástrofes naturales. En el contexto de los talleres de producción, se observan caída de metales, fallas y 
piezas abandonadas durante el proceso de fabricación o también herramientas más o menos deterioradas, lo cual constituye una fuente documental de gran importancia para nuestras investigaciones. Los actos sociales que conllevan a la salida del metal de los circuitos normales de reciclado son las deposiciones practicadas en sepulturas, ya sean inhumaciones o incineraciones, o rituales de abandono $u$ ofrendas en santuarios. La aclaración social de estas prácticas tiene como consecuencia la no representatividad de estos vestigios en comparación a lo que eran su uso en la sociedad que se estudia.

\section{2. Una lectura tecnológica de todos los tipos de restos materiales}

La primera etapa de caracterización consiste en determinar el número de piezas que constituye un objeto. Para responder a la pregunta considerada, se deberán realizar exámenes visuales, a simple vista y con lupas binoculares así como, cuando es posible, exámenes radiográficos. Hay que subrayar que una buena calidad de acabado del objeto, asociada a una superficie deteriorada, es decir, en parte cubierta por productos de corrosión mezclados con pocos o muchos sedimentos, hacen a veces difícil la distinción de las diferentes piezas. La segunda etapa consiste en determinar las aleaciones y los procesos de fabricación empleados para la realización de cada pieza metálica que constituye el objeto. Esta «lectura tecnológica», que explota los recursos de la ciencia actual de los materiales, se aplica a objetos metálicos antiguos, así como a las herramientas, dispositivos y estructuras que participan en su producción, como por ejemplo, moldes $u$ hornos. Las informaciones obtenidas permiten entonces reconstruir cadenas operativas de fabricación.

La excavación de talleres de producción es una fuente documental de gran importancia. Vestigios pocos «prestigiosos» como desechos, subproductos, fallas de fabricación, etc. suelen ser registrados en este tipo de contexto. El estudio de estos vestigios, así como de las herramientas utilizadas (metálicas o no) y de los dispositivos (hornos, por ejemplo), aporta informaciones importantes. Por ejemplo, trazas de golpes de martillo en el metal trabajado aportan informaciones sobre la parte activa del martillo utilizado, mientras que el martillo en sí ya no existe o bien queda sin partes identificables. De igual manera, la estructura de los talleres y la organización del espacio de trabajo de estos solo pueden ser estudiadas por medio de la excavación minuciosa de este tipo de vestigios.

Por supuesto, cuando existen, la iconografía y los textos son otros tipos de fuentes importantes. La fuente arqueológica está constituida por documentos que pueden ser de varios tipos (acabados, piezas en proceso, desechos, subproductos, etc.) enteros o fragmentarios, así como también por restos de estructuras (muros, fosas, hornos etc.); y finalmente por la epigrafía, como inscripciones sobre monumentos, monedas etc. Los textos literarios, además de la correspondencia y los documentos contables constituyen principalmente la fuente histórica. La fuente iconográfica está formada por las imágenes, cualquier sean sus soportes; pueden aparecer sobre 
edificios (pinturas murales, por ejemplo), en objetos de metal (como monedas) o realizadas sobre otros materiales.

Entre otros aportes, la experimentación es otro recurso para probar y validar las hipótesis avanzadas. Los productos, subproductos, las herramientas y dispositivos empleados, así como los vestigios que resultan de operaciones de arqueología experimental, pueden ser sometidos a la misma metodología de estudio que los vestigios del pasado, con el fin de controlar los resultados. El protocolo experimental permite también acceder, en ciertas medidas, al parámetro de tiempo. El tiempo necesario para la fabricación depende de la virtuosidad, la organización y el objetivo en términos de producción única o en serie; sin embargo, es solamente una manera muy general de poder estimar la productividad.

\section{LOS MODOS DE FABRICACIÓN}

Para pretender «leer» un objeto es indispensable conocer los posibles procesos. Uno de los problemas básicos es que siempre existen diferentes maneras de fabricar el modelo de un objeto en metal. La figura 1 ilustra las cuatro principales formas posibles de realizar operaciones de fundición, de deformación plástica y de «maquinaria», es decir con un torno. En los dos primeros esquemas, se privilegia la deformación plástica. Un trabajo en recopado (raising), el cual permite cerrar una forma con pocas variaciones de espesores de la lámina, se ilustra en el esquema 1; un trabajo en expansión, es decir, en embutido (sinking), que reduce el espesor de la lámina produciendo el inflamiento de la forma (como una pelota), corresponde a la ilustración 2. Para los modos 3 y 4, ilustrados abajo, la fundición es el proceso dominante utilizado para la fabricación de las piezas; el esbozo inicial es cercano, hasta muy similar, al producto final. En uno de los casos no existe ninguna aplicación de un proceso de deformación plástica; en el otro, será una etapa intermediaria. Siempre se trata de esquemas de principios, todas las variaciones son posibles. Por ejemplo, el proceso de fundición ilustrado es del tipo cera perdida; el artesano podrá elegir otro proceso.

\section{1. La fundición}

Para las aleaciones que se pueden derretir1, y por lo tanto, vaciar, se pueden distinguir dos grandes categorías de procesos de fundición: la fundición en molde permanente y la fundición en molde de utilización única. En esta última clase, encontramos los procesos de la «cera perdida», de la «fundición en arena»y con «molde ensamblado en cerámica». La fundición en molde permanente implica un molde desmontable y re-utilizable, siempre en varias piezas (idos por lo menos!), cuyo material debe resistir a las coacciones, térmicas y mecánicas, del metal en

1 El hierro, que funde a $1535^{\circ} \mathrm{C}$, es infusible para las sociedades antiguas; los dispositivos utilizados en estas culturas no permiten sobrepasar $1200^{\circ} \mathrm{C}$ de temperatura. 


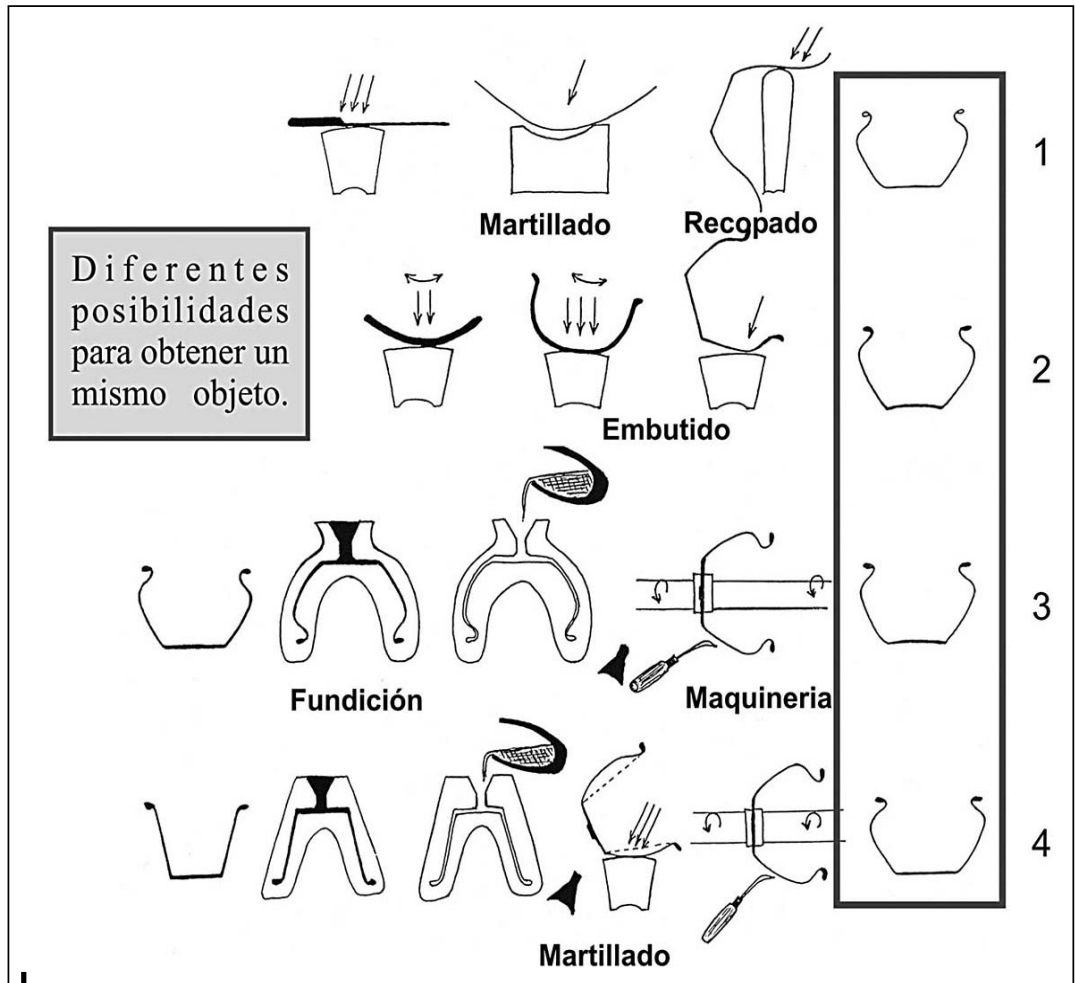

Figura 1 - Esquemas de las principales cadenas operatorias posibles para la fabricación de un mismo tipo de objeto en aleación de cobre

Según Dubos, 1989

fusión durante la colada propiamente dicha. Este tipo de proceso permite, siempre que el molde sea utilizable, producir piezas similares; sin embargo se deben hacer dos observaciones. En primer lugar, el objeto que se produce sólo existe en negativo. En segundo lugar, la producción en serie está limitada por el hecho de que, para cada colada en el molde, se debe esperar que el metal esté solidificado antes de desmoldarlo y volver a colar otra pieza; por lo tanto, la productividad es baja. En cambio, los procesos en moldes no permanentes, es decir, utilizados para una sola operación de vaciado, son procesos de copias, cuya productividad puede abarcar un rango importante. En efecto, con la «fundición en arena» (molde crudo) o con un «molde ensamblado en cerámica» (molde cocido) el original del objeto que debe ser producido - el modelo - es un positivo rígido realizado con cualquier tipo de material capaz de resistir lo suficiente (madera, tierra secada o cocida, metal, etc.). El molde se desmonta una vez, para recuperar el modelo; luego, se reensambla. Después, tras la colada y el enfriamiento del metal, se destruye para recuperar el producto metálico. En el proceso de la «cera perdida», el modelo en cera se destruye por fusión - es por eso que decimos que la cera se pierdepero el modelo puede también resultar de una operación de fabricación en serie. Todo depende de los objetivos que persiguen los artesanos. Por ejemplo, se trata 
de una operación singular: se fabricará un modelo en cera una sola vez, luego se obtendrá la pieza en metal por fundición. O bien se pueden producir «ceras» en serie a partir de un molde reutilizable. La impronta puede ser creada en negativo. Sin embargo, el parámetro de la temperatura es menos apremiante para la cera (cerca de $100^{\circ} \mathrm{C}$ ) que para una aleación de cobre o aleaciones preciosas (cerca de $1000^{\circ} \mathrm{C}$ ); la consecuencia es que el molde puede ser de madera, por ejemplo. Si el modelo original fuera en positivo y rígido, puede ser modelado con una tierra plástica, por ejemplo. A partir de este molde intermedio, se puede producir «ceras» - es decir, modelos en cera- en grandes series para luego vaciarlas en «cera perdida». La utilización de la «fundición en grapas», es decir, que un mismo molde asocia varias piezas que serán vaciadas en una sola operación de colada, desmultiplica la productividad. Los testigos arqueológicos muestran, sin ninguna ambigüedad, que culturas europeas del final de la edad del hierro y del periodo romano han practicado el proceso anteriormente descrito para producir más, con mayor rapidez y probablemente a menor costo (Pernot 1998; Chardron-Picault \& Pernot, 1999: 159-168).

Uno de los elementos principales de un taller de fundición de aleaciones preciosas o con base de cobre, es un horno de fusión que debe poder funcionar sin problema a una temperatura hacia $1000^{\circ} \mathrm{C}$. A este nivel de temperatura se forman naturalmente a partir de las paredes del horno (necesariamente ricas en materias silíceas), cenizas de combustible (carbón de madera) ricas en óxidos de potasio que tienen el rol de fundente, y de óxidos metálicos, vitrificaciones, elementos de materia parcialmente transformados en vidrio. Son testigos arqueológicos de gran importancia para comprender el funcionamiento del taller.

\section{2. La deformación plástica}

Cuando un elemento de volumen de un material es sometido a una fuerza, presenta un cambio en su forma. Una vez que la fuerza deja de ser aplicada y si el material recupera su forma inicial, entonces se trata de una deformación elástica. Si el material presenta una deformación residual permanente se trata entonces de una deformación plástica. Generalmente las aleaciones metálicas presentan un comportamiento elástico cuando están sometidas a fuerzas débiles (las vibraciones de una cuerda que oscila o de una campana que timbra por ejemplo); están en un ámbito de deformación plástica cuando las fuerzas aplicadas son más fuertes. Es el nivel de tensión que explica los diferentes fenómenos; la tensión, fuerza añadida a la superficie, es homóloga a la presión. Si la tensión llega a otro nivel, se produce una ruptura. Un material que no presenta un ámbito de deformación plástica se dice frágil; el vidrio es un ejemplo. Una deformación demasiado avanzada conduce a pesar de todo a la ruptura. Sin embargo, si la deformación se detiene antes de que se alcance un daño irreversible, el material puede recuperar su capacidad de deformación si fuera sometido a un recocido. Un recocido es un tratamiento térmico (o calentamiento) efectuado a altas temperaturas pero siempre debajo de la temperatura de inicio de la fusión. Para una aleación a base de cobre, se realiza entre 600 y $700^{\circ} \mathrm{C}$ aproximadamente, durante algunos minutos. La gran mayoría 
de los metales y aleaciones presenta una capacidad de deformación plástica a temperatura ambiental explotable para asegurar, por medio de pasos que alternan una deformación y un recocido, una etapa que puede ser muy importante en el proceso de fabricación. En otros casos, será más provechoso trabajar la deformación en altas temperaturas, es decir «en caliente»; la forja del hierro es un ejemplo. Las aleaciones preciosas y a base de cobre se trabajan a temperatura ambiente (llamado «en frío») por razones vinculadas a sus propiedades. Es también necesario tener en cuenta la masa y la forma del objeto. En efecto, un pequeño objeto (menos de $100 \mathrm{~g}$, por ejemplo) con una importante relación superficie/volumen (un alambre delgado o una lámina delgada, por ejemplo) enfría demasiado rápidamente, en relación al tiempo de trabajo. No hay inercia térmica suficiente para hacer posible un trabajo a temperatura casi constante.

La técnica, recurriendo al fenómeno² de deformación plástica, que es la más utilizada en las culturas antiguas, es el martillado; la pieza es martillada con un martillo sobre un yunque. Los tipos de herramientas, que sean para las herramientas llamadas «durmientes» o «activas», son numerosas y variadas (véase por ejemplo: Maryon, 1971, cap. XI). El artesano que martilla el metal debe necesariamente disponer de herramientas adaptadas con precisión a cada etapa de fabricación y fabrica él mismo la mayoría de sus herramientas que pueden ser de metal, de piedra o de madera dura. La cantidad de deformación total utilizada puede corresponder a una reducción del grosor de factor 10. En las culturas de la Europa occidental, hace aproximadamente 3000 años, una lámina de 0,5 mm de grosor se obtiene comúnmente a partir de un esbozo de fundición de $5 \mathrm{~mm}$ de grosor inicial (Pernot, 2000).

Un horno de recocido es una estructura de combustión que funciona a aproximadamente $700^{\circ} \mathrm{C}$; es, en general, una estructura ampliamente abierta, la operación de recocido se realiza sobre las mismas brasas para que el metal esté en una atmosfera químicamente reductora (el agente reductor es el monóxido de carbono) y para que se oxide lo menos posible. Recordemos que $700^{\circ} \mathrm{C}$ es, más o menos, la temperatura alcanzada por el brasero rojizo de un fogón que funciona sin dispositivo que ayuda a aumentar la ventilación. Así, en términos de vestigios arqueológicos, dicho tipo de horno no se distingue claramente de un fogón de uso doméstico utilizado para calefacción o en la cocina. Es la confluencia de varios tipos de vestigios que lleva a interpretar un espacio como el de un taller y por lo tanto, a interpretar un fogón como horno de recocido.

\section{3. Los acabados}

La tercera etapa de fabricación de los objetos, y no la menos importante, es la de los acabados. Se pueden distinguir tres campos: la decoración, la unión de las piezas y los tratamientos de superficie.

2 La deformación plástica es un fenómeno que los artesanos supieron explotar en técnicas de martillado, doblado, torsión etc. 
La decoración de una pieza metálica, más allá de su propia forma, se garantiza muchas veces por medio de relieves más o menos profundos. Estos últimos pueden haber sido previamente realizados sobre un modelo, antes de la fundición. Pueden también haber sido realizados por deformación plástica del metal, con la ayuda de cinceles o punzones para realizar incisiones o motivos contrastados sin quitarle materia, o también utilizando la técnica del repujado sobre láminas delgadas. El proceso del grabado, que consiste en quitar virutas del material para realizar diseños, implica la utilización de herramientas cortantes, particularmente adaptadas, cuya presencia es escasa en las culturas antiguas. Sin embargo, retirar material para realizar relieves, que pueden incluso atravesar todo el grosor de la lámina (el calado), siempre es posible; en particular cuando se asocian la perforación y la abrasión, el campo de posibilidades es inmenso. Observamos que relieves muy bajos, de algunas decenas de micras de desnivel, conducen a un enganche de luz muy diferente del producido sobre una superficie pulida como un espejo. En este último caso se produce un fenómeno de reflexión, mientras que en el primer caso se produce una difusión de la luz. El añadido de materiales diversos y colores variados (otros metales, piedras, hueso, marfil, coral, etc.) realizado en frío con pegamento, remaches, ensarte y engarce son comunes en las prácticas de todas las culturas. Una fase de cocción a altas temperaturas diferencia los añadidos de materias en caliente como en la técnica del esmaltado que utiliza la inclusión de vidrios de todos colores, o la técnica del nielado, que consiste en incrustar un sulfuro simple o mixto de cobre, plomo y plata (cristalizado y no vítreo) de color negro en las partes hondas de piezas de aleaciones preciosas o a base de cobre.

Cuando el objeto está constituido por diferentes piezas, la unión de estas puede realizarse con tres grandes tipos de procesos. La práctica del «vaciado secundario» consiste en vaciar una segunda pieza sobre una primera previamente fabricada; la utilización de este proceso ha sido comprobado en la elaboración de cabezas de alfileres de la edad del Bronce de Europa Occidental (Armbruster \& Pernot, 2006). Se pueden emplear diferentes procesos mecánicos: remache, engaste, uniones con anillos, etc. Finalmente, la tercera categoría es la de los procesos térmicos, que agrupa las soldaduras directas e indirectas. La soldadura indirecta (brazing) es una unión con un metal aportado que funde a temperatura claramente más baja que aquélla de las piezas por juntar, por ejemplo una aleación plomo-estaño (que funde a aproximadamente $200^{\circ} \mathrm{C}$ ) se utiliza ampliamente para unir piezas en aleaciones a base de cobre (que funden a aproximadamente $1000^{\circ} \mathrm{C}$ ). Una soldadura implica la fusión local de los bordes de las piezas que se tienen que juntar, con o sin el aporte de un metal. Antiguamente, en el mundo occidental, las diferentes piezas que constituyen las grandes estatuas de bronce, se unían por medio del «vaciado secundario» de una aleación del mismo tipo en pequeñas palanganas preparadas al nivel de los bordes de las piezas (Formigli, 1999: 326).

La superficie del metal siempre es objeto de mucho cuidado. Puede estar cubierta de una capa de un metal diferente del que constituye la pieza; en las culturas antiguas, puede ser un dorado, un plateado, un estañado o tratamiento de superficie con cobre o bronce para cubrir las piezas de hierro (Chardron-Picault 
\& Pernot, 1999: 185-187). Se puede realizar una mise en couleur de la superficie por medio de un ataque químico, que produce una pátina; esta práctica muy corriente hoy en día (quizás demasiado corriente, porque el metal ya no aparece) fue utilizada a veces en el mundo romano con cobre patinado en negro para realizar incrustaciones polícromas sobre piezas de bronce. Es importante notar que enchapados o pátinas parciales, en oposición a zonas no tratadas químicamente, permiten obtener efectos decorativos. Finalmente, el pulido es una práctica recurrente en los talleres que trabajan el metal. Existen razones técnicas; por ejemplo, durante el proceso de martillado es preferible que el metal no sea oxidado para evitar que penetren fragmentos de óxidos en el metal. Sin embargo, en las culturas antiguas, muchas veces se valoró el metal porque brillaba. Los textos de Homero siempre enfatizaban que el bronce que constituyía las armas era brillante, relumbrante, centelleante, rutilante...

\section{LA CIENCIA DE LOS MATERIALES}

Los medios de la ciencia contemporánea de los materiales permiten caracterizar las aleaciones y los procesos que se emplearon para realizarlos.

\section{1. Observaciones diversas}

El primer paso — siempre es útil decirlo, aunque sea evidente- consiste en observar atentamente el objeto a simple vista y con lupas binoculares. La figura 2 presenta una copa de la edad de Bronce final que ha sido encontrada en el centroeste de Francia (Piningre, 2002); el diámetro del objeto es de cerca de 135 mm

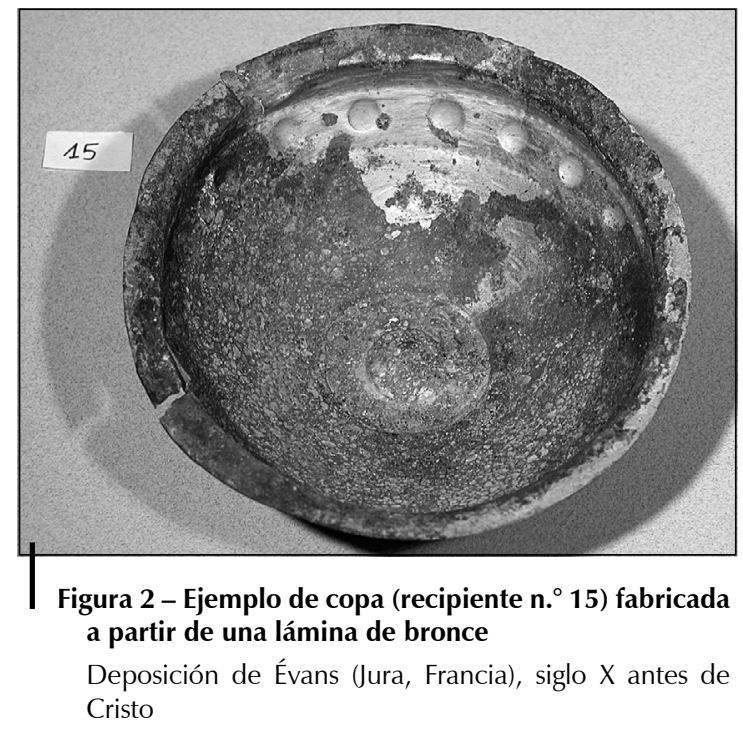


y la aleación que constituye la lámina es un bronce con aproximadamente $12 \%$ de estaño. La decoración de este tipo de copa ha sido realizada por deformación plástica, con la técnica del repujado; está compuesta por puntos hemisféricos abollados, cuyo diámetro es de $5 \mathrm{~mm}$ aproximadamente, y de líneas de pequeños puntos, de forma cónica, que sobresalen en $1 \mathrm{~mm}$, más o menos (fig. 3). Los exámenes con lupa muestran claramente que estos dos tipos de motivos decorativos no se realizaron con las mismas herramientas. Los puntos hemisféricos repujados están claramente delimitados por un círculo, que en sección, corresponde a una ruptura de pendiente a ángulo afilado; el dispositivo utilizado comprendía pues un punzón y una matriz, ambos realizados en materiales rígidos, probablemente bronce (fig. 3a). Los puntos muestran un relieve mucho más suave; se realizaron con un punzón de forma redondeada (cuya punta no es puntiaguda puesto que no se trata de perforar la lámina), probablemente metálico. La lámina se apoya sobre un material plástico relativamente blando, como madera o plomo (fig. 3b). Estos exámenes permiten obtener informaciones sobre tipos de herramientas, independientemente de su descubrimiento.

Exámenes radiográficos aportan muchas veces informaciones muy útiles. La figura 4 presenta imágenes obtenidas a partir de tres recipientes procedentes de la deposición (u ofrenda) de Évans (Jura, Francia). Se observa muy claramente que la manera de conducir las últimas fases del trabajo del martillado ha sido
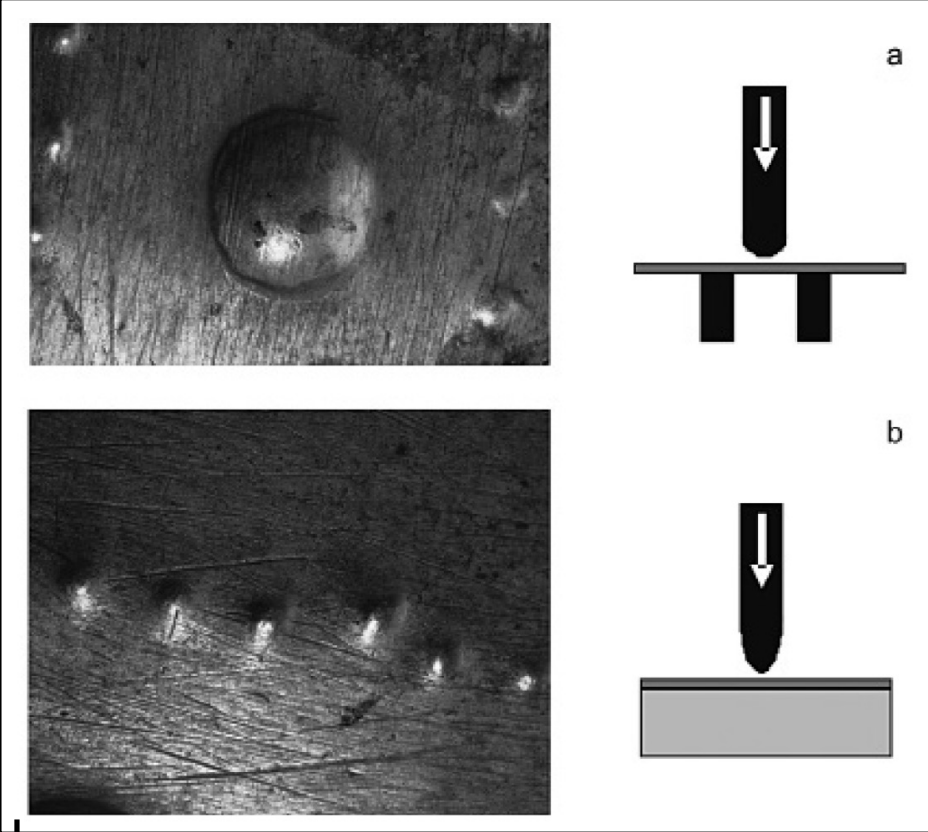

Figura 3 - Vistas del exterior de elementos decorativos de una copa (recipiente n. ${ }^{\circ} 12$ )

Deposición de Évans (Jura, Francia); esquema ilustrativo de las herramientas utilizadas para su fabricación 
diferente para cada objeto. En todos los casos, se trata de un trabajo con un martillo de boca alargada, tipo martillo de recopado. Para el recipiente n. ${ }^{\circ} 15$, los golpes se han sucedido en círculos concéntricos; para el recipiente $n .^{\circ} 3$, los golpes se han realizado formando líneas pseudo radiales. Finalmente para el vaso n. ${ }^{\circ}$ 38, el esquema de trabajo es bidireccional, dos series de golpes se entrecruzan sobre líneas radiales y circunferenciales. El significado histórico, en términos cronoculturales de esas observaciones aún no se comprende con claridad; es necesario generalizar la práctica de la radiografía para lograr avances.

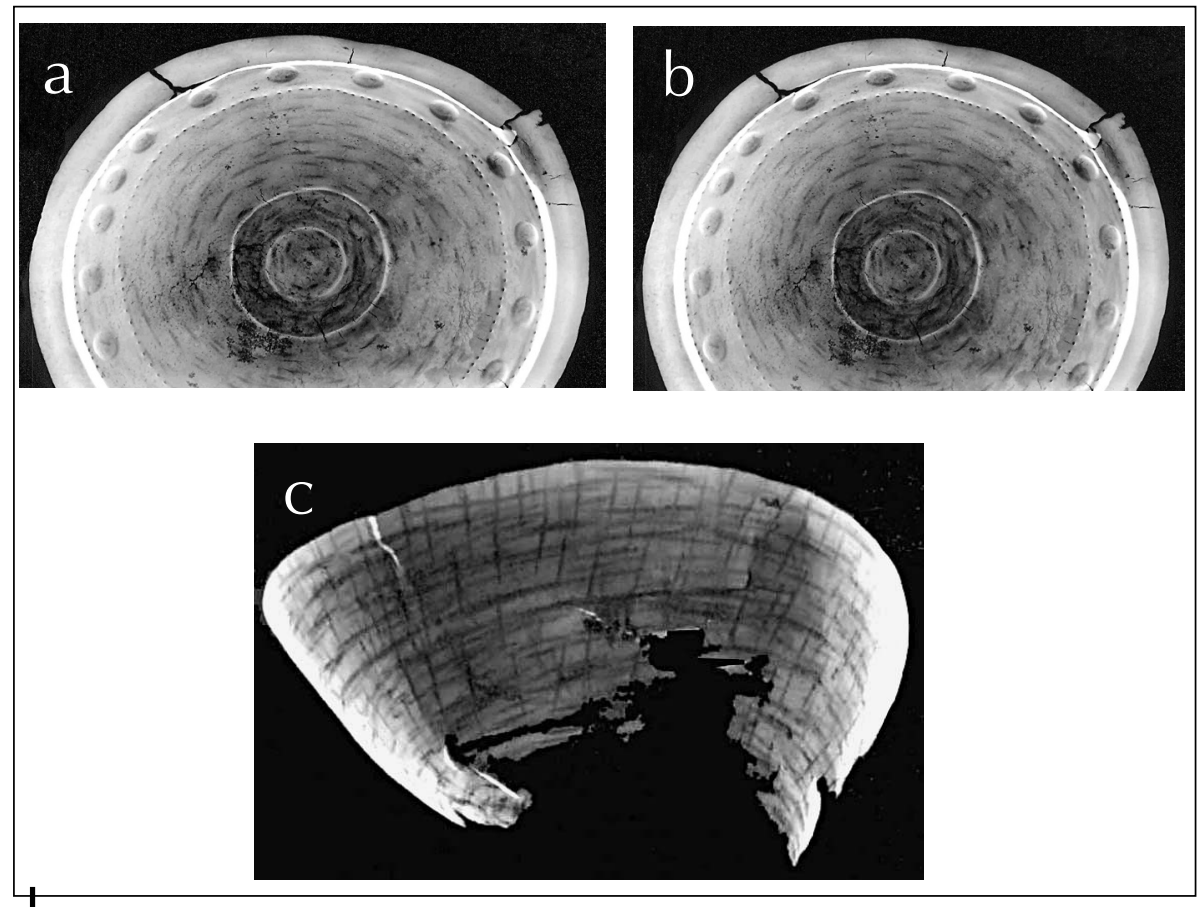

Figura 4 - Imágenes radiográficas de tres objetos diferentes de la deposición de Évans (Jura, Francia): a: recipiente 15; b: recipiente 2; c: recipiente 7

\section{2. Exámenes metalográficos}

La lectura tecnológica de un objeto puede ser profundizada por el estudio de cortes metalográficos (Pernot, 1999). El examen de estos, por medio de observaciones realizadas con microscopios, ópticos y electrónicos de barrido, permite acceder a la microestructura del material. Un material metálico sólido cristalino está generalmente constituido de granos, eventualmente de varias fases diferentes. Las características de forma de estos granos: naturaleza, tamaño, forma, repartición, etc. constituyen su descripción microestructural. Se deben realizar muestras de las piezas que se desean estudiar; un volumen de aproximadamente algunos milímetros cúbicos es suficiente. Cada muestra ha 
sido previamente incorporada a una resina para facilitar la manipulación; luego, se pule cuidadosamente. Los siguientes pasos se realizan con abrasivos cada vez más finos hasta obtener un pulido tipo «espejo»; por ejemplo, se puede realizar el acabado con pasta cargada de granos de diamante de un tamaño de $0,25 \mu \mathrm{m}$. La orientación de la parte pulida debe ser cuidadosamente seleccionada con respecto a los ejes principales de la pieza para obtener informaciones pertinentes; por ejemplo, para una lámina, se elige el plano de la lámina o bien la sección perpendicular, dos cortes de la misma muestra pueden también estar preparados. Los exámenes directos, con microscopio, de secciones pulidas dan acceso a la microestructura de inclusiones: las diferentes fases presentes son visibles debido al contraste de sus diferentes poderes de reflexión, de absorción o de difusión; se recurre casi siempre a un ataque químico de la superficie con un reactivo ácido, lo que hace visible las juntas de los granos del metal y acceder a la microestructura granular.

El examen de cortes metalográficos en microscopía electrónica de barrido permite realizar, por medio de un dispositivo de espectrometría de rayos $X$ asociado (EDXS), análisis de composición sobre fases visualizadas con el sistema de imagen. Esto hace posible realizar análisis globales, es decir, sobre una superficie, conteniendo en proporciones estáticamente representativas todas las fases presentes e integrando los eventuales gradientes de composición, así como análisis puntuales, sobre una inclusión por ejemplo. La visualización de la zona analizada permite tomar en cuenta exclusivamente el metal sano y así obtener un resultado más representativo porque no se toma en cuenta la fracción de zonas corroídas. La corrosión implica la pérdida de una parte de cobre; la presencia, aunque sea parcial, de productos de corrosión en el volumen analizado falsificaría, en exceso, el contenido en estaño.

\section{3. Un ejemplo conocido}

Para ilustrar la caracterización microestructural, tomamos el ejemplo de la Crátera de Vix. La figura 5 presenta la crátera al momento de su descubrimiento en la tumba de Vix, en Châtillon-sur-Seine (Côte-d'Or, Francia). Fechado al final del siglo VI antes de Cristo, se trata del vaso de bronce más grande elaborado en el mundo griego (su capacidad es superior a $1 \mathrm{~m}^{3}$ ) y que se conoció a partir de la documentación arqueológica (Rolley, 2003). Su estudio técnico indica que está compuesto por 37 piezas, sin tomar en cuenta los remaches de unión y la tapacoladora. Todas las piezas son de bronce con un contenido por medio de $10 \%$; dos de ellas han sido examinadas con microscopio metalográfico (Pernot, 2003).

Dos piezas semicirculares, decoradas de prismas, están fijadas con remaches debajo del borde del vaso; se ha preparado una sección metalográfica perpendicular a la punta de uno de los prismas (fig. 6). La microestructura observada es típica de un estado de fundición: muestra granos de forma dendrítica (cuyos contornos están ondulados) en los cuales la segregación (variación del contenido en estaño), que resulta de la solidificación, es visible por diferencias de colores (del beige al marrón). Las inclusiones presentan dos colores, se trata de nódulos que corresponden a la 


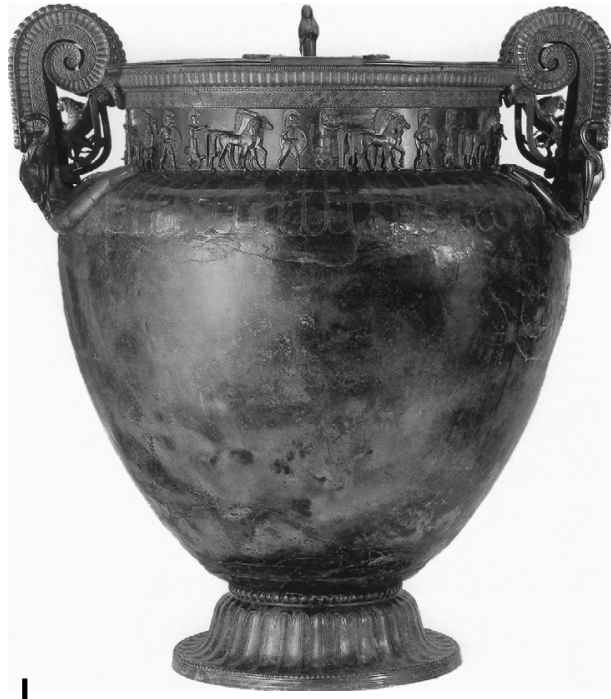

Figura 5 - La crátera de Vix (Châtillon-surSeine, Côte-d'Or, Francia)

Mide 1,63 $\mathrm{m}$ de altura con un peso total de $208,6 \mathrm{~kg}$. Fabricado en el mundo griego al final del siglo VI antes de Cristo. Este recipiente fue exportado a un pueblo celta

mezcla de las fases $\alpha$ (gris oscuro) y $\delta$ (gris claro) que resultan de la reacción eutectoide que tuvo lugar a $520^{\circ} \mathrm{C}$ durante el enfriamiento. Las finas estrías que atraviesan los granos atestiguan la realización de un suave trabajo de deformación plástica, posterior al enfriamiento. Estas estrías resultan del retoque de los motivos decorativos por cincelado, operación destinada a acentuar el relieve de los prismas. Notamos que la deformación generada por los golpes del cincel ha inducido fracturas claramente visibles en los nódulos de la mezcla eutectoide.

Otra sección permite observar la microestructura del corte efectuado al nivel del cuerpo del recipiente (fig. 7). La forma poligonal de los granos indica que la aleación se encuentra en un estado final recristalizado; las inclusiones de sulfuros de cobre son fuertemente alargados: aparecen en la imagen como líneas oscuras. Las características de esta microestructura demuestran que la lámina delgada (aproximadamente $1 \mathrm{~mm}$ de grosor) ha sido obtenida por martilleo. Se realizó, a partir de un esbozo previamente vaciado, mediante pasos de deformación alternados con recocidos de recristalización; la aleación homogeneizada por el trabajo ha sido dejada en un estado final recocido. Las

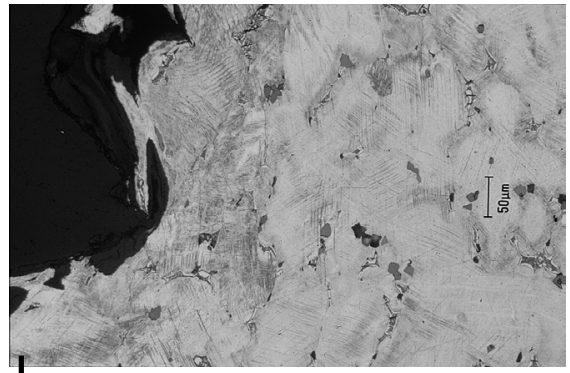

Figura 6 - Observación en microscopio óptico, tras un ataque químico, de una sección perpendicular a la punta del prisma de una pieza de la cornisa que estaba fijada con remache bajo el borde de la crátera de Vix (fig. 5)

Las inclusiones de sulfuros de cobre, de color gris, son de forma casi globular

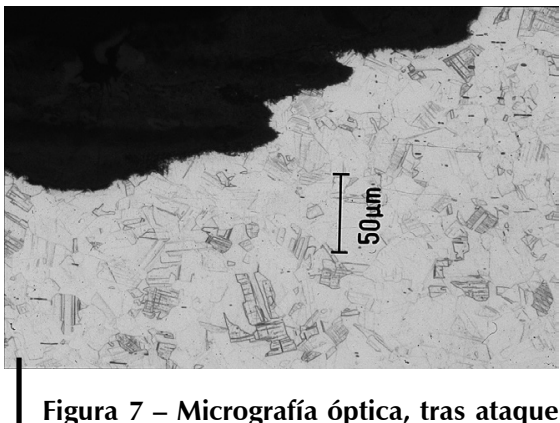
químico, de la sección de la lámina del cuerpo de la crátera de Vix (fig. 5)

El plano de observación es perpendicular a una de las incisiones que forman los motivos decorativos de lengüetas, sobre el hombro del recipiente. Entre los granos recristalizados, las estrías oscuras y horizontales, se encuentran inclusiones de sulfuros de cobre fuertemente alargadas 
incisiones que forman la decoración de lengüetas sobre el hombro del vaso han sido realizadas sin deformación plástica porque las inclusiones de sulfuro de cobre son rectilíneas y no curvadas; no se trata de un trabajo de cincelado, sino más probablemente de un trabajo de abrasión.

Los resultados del estudio metalográfico permiten obtener diversas conclusiones, de las cuales cabe resaltar dos:

- La parte principal de la crátera, el recipiente de 1100 litros de capacidad, ha sido fabricado por medio del martillado. Esta notable fabricación, la cual pone en juego cerca de $60 \mathrm{~kg}$ de metal, revela el alto nivel de conocimiento del artesano o de los artesanos, ya que no solamente se debe martillar una pieza de grandes dimensiones, sino también realizar una instalación (un horno) que permite procesar adecuadamente los recocidos. Así, debe ser comparada con los demás recipientes más pequeños y no con piezas de grandes estatuas obtenidas por fundición.

- Al comparar las figuras 6 y 7 , se observa, a través de la fracción de superficie de las inclusiones de sulfuro de cobre, que en estas dos aleaciones de aproximadamente $10 \%$ de estaño, el contenido de azufre es claramente menor en la lámina que forma el cuerpo del recipiente que aquello que constituye el borde. Esta observación está comprobada por los análisis que indican que el bronce de la cornisa ha sido preparado con un cobre «comúnmente limpio», que contiene aproximadamente 0,1 \% de azufre, mientras la aleación que constituye el cuerpo del recipiente es «notablemente limpio», con 10 veces menos de azufre. Los artesanos muy probablemente han utilizado un cobre de alta pureza para elaborar el bronce de la pieza más delicada que debían elaborar, mientras que han empleado un cobre de calidad regular para elaborar las piezas producidas por vaciado. Esto se puede explicar perfectamente por el hecho de que la pureza no es un parámetro crítico para las piezas vaciadas, mientras que sí lo es para el trabajo de deformación plástica. En efecto, durante la deformación plástica todas las inclusiones son susceptibles de generar concentraciones de tensiones al nivel de su interfaz con la matriz, creando sitios potenciales para el inicio de fisuras. Mientras más grande sea el contenido de azufre, más grande será el riesgo de que las fisuras se propaguen para llegar al resultado de una ruptura.

Así, en la Europa Occidental del siglo VI antes de Cristo, suelen aparecer diferentes ofertas de calidad de cobre en el mercado, los cuales debían tener, naturalmente, precios variados. Entre los conocimientos aplicados en un taller, se encuentra también aquél que consiste en tener un buen conocimiento de los proveedores de materias primas y por lo tanto, de la calidad de los materiales propuestos, en un contexto de circuitos de confianza en paralelo a los controles de propiedades mecánicas.

\section{LOS TALLERES DE FABRICACIÓN}

La iconografía de la Antigüedad nos ofrece algunas imágenes de talleres de metales. Desde la sepultura de Rekhmiré en el Egipto del siglo XV a.C., hasta la 
estela romana de Aquileia (Italia), pasando por el fresco de los amorini orafi de la casa de Vettii, en Pompeya, fechado antes del 79, cerámicas de la Grecia del siglo $\checkmark$ a.C., como la copa ática llamada «de la fundición» que se conserva en Berlín (Rolley, 1983: 26-27), ilustran este tipo de actividad artesanal; sin embargo, estas raras representaciones son muy convencionales y a veces poco realistas.

La excavación de talleres pertenecientes a culturas antiguas sigue siendo la fuente documental más rica; existen vestigios - la experiencia arqueológica no deja de demostrarlo - pero es necesario saber identificarlos porque son a menudo tenues y/o muy degradados. Como quiera que estén, se han recuperado casi todos los elementos metálicos para ser reciclados; las herramientas, así como todos los dispositivos móviles o en estado de funcionamiento, han sido llevados al momento de abandonar el sitio. Los vestigios no son, en muchos de los casos, espectaculares; en particular porque las pequeñas unidades de fabricación de objetos pequeños corresponden solamente a espacios de 20 a $30 \mathrm{~m}^{2}$, y en ocasiones, incluso menos, donde funcionaban hornos de pequeñas dimensiones. Los restos de hornos de ceramista son generalmente más grandes y mucho más fáciles de interpretar que aquellos de metalurgista.

Desde los últimos veinte años, se han podido llevar a cabo y publicar diversas excavaciones de talleres de metales y aleaciones no ferrosos. En Francia, y por las aleaciones a base de cobre, se pueden señalar los siguientes sitios arqueológicos: Les Rochereaux, cerca de Poitiers, para el siglo II a. C. (Toledo I Mur \& Pernot, 2008), La porte du Rebout en el monte de Beuvray para el siglo I a. C. (Pernot, 1993; Pernot, 1998), Le lycée militaire, en Autun, para el periodo romano (Chardron-Picault \& Pernot, 1999), así como La rue de Saint-Malo, en Rennes

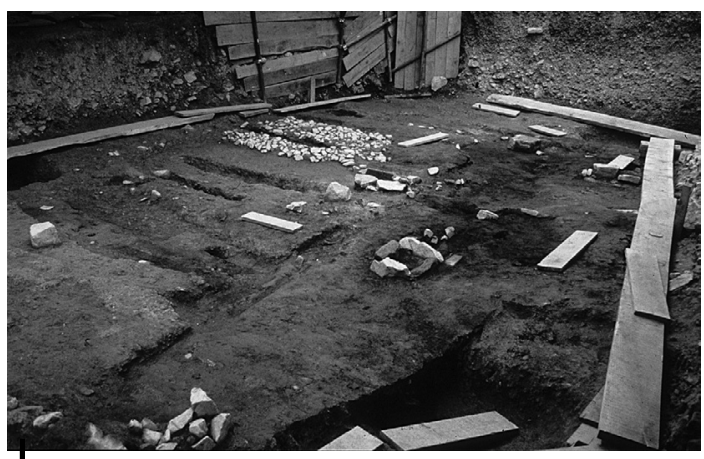

Figura 8 - Taller de bronce de La porte du Rebout sur le mont Beuvray (Nièvre et Saône-et-Loire, Francia)

Estado de excavación final de la capa de ocupación de funcionamiento, de los años 40-20 antes de Cristo. La parte dedicada a la fundición aparece, con un suelo negro, en el primer plano y a la derecha. La parte reservada a las operaciones de moldeado y de acabados se observa en el segundo plano; la superficie del espacio visible en la fotografía es aproximadamente de $25 \mathrm{~m}^{2}$
(Mothes \& Pernot, 2008) y Le Grand-Hôtel de Bordeaux, en Bordeaux (Pernot et al., 2007). En Italia, se ha estudiado un taller de trabajo en plomo, en Ercolano, cerca de Nápoles, del primer siglo de nuestra era (Monteix et al., 2008).

El taller de artesanos de bronce de La porte du Rebout en el monte de Beuvray (Nièvre et Saône-et-Loire, Francia) da un ejemplo completo de resultados obtenidos por la metodología que consiste en interpretar simultáneamente los vestigios muebles e inmuebles. Además de los vestigios tomados en cuenta en los estudios arqueológicos corrientes (objetos acabados, más o menos fragmentados), hemos centrado nuestra atención especialmente en los vestigios de la fabricación de piezas metálicas así como también de fragmentos de crisoles, de 
moldes o de paredes de hornos, cuando se tratan de vestigios de arcilla cocida; y de piezas de metal, además de fragmentos de objetos, es decir principalmente desechos de trabajo y algunas piezas abandonadas en el proceso de fabricación, así como algunas herramientas, mayormente fragmentadas. La figura 8 presenta una vista general del estado de excavación correspondiente a lo que subsiste del espacio de trabajo; el estudio arqueológico de recipientes en cerámica y objetos metálicos (monedas y fíbulas) indica que la fase de funcionamiento se sitúa entre los años 40 a 20 antes de Cristo. La figura 9 ilustra los dos tipos de hornos utilizados. La parte útil del pequeño horno de fusión de la figura 9a es sensiblemente cuadrada, con un lado de $25 \mathrm{~cm}$ aproximadamente; en éste se puede derretir algunas centenas de gramos de metal. Un espacio contiguo es probablemente destinado a posicionar los moldes sobre el brasero y mantenerlos calientes durante la operación de colada. El horno rectangular de la figura 9b, con una superficie de $50 \mathrm{~cm}$ sobre $25 \mathrm{~cm}$, en parte construido con tejas, ha calentado menos que el anterior; se interpreta como un horno de recocido. Notamos que la interpretación como horno de recocido solo es posible gracias al contexto de descubrimiento; con respeto a la temperatura de funcionamiento — cerca de $700^{\circ} \mathrm{C}$ — un fogón de este tipo, interpretado fuera de su contexto sería entendido como vinculado a usos domésticos (preparaciones culinarias u horno de calefacción). Las dimensiones de estos hornos, así como la capacidad de los crisoles indican que se producían pequeños objetos (menos de $300 \mathrm{~g}$ de metal). Los análisis MEB-EDS en laboratorio de la composición de las aleaciones demuestran que el latón con 20 \% de zinc era mayormente vaciado, martillado y recocido en este taller. Objetos en proceso de fabricación abandonados o perdidos en los acondicionamientos del suelo del taller indican que las fíbulas constituían una parte de la producción.

Es posible recomponer, gracias a un gran número de elementos analizados, el estado del presente taller y su rango de producción. En una construcción de tierra y madera, cerrado y abierto, una pieza, dividida en función de las etapas de fabricación, agrupa todas las fases del trabajo (fig. 10). La organización del espacio
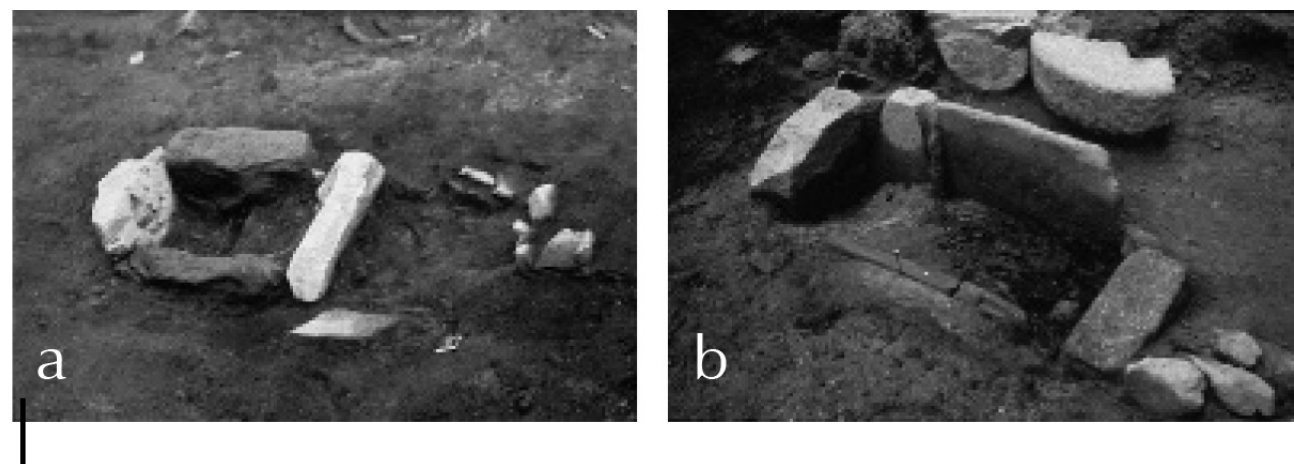

Figura 9 - Vistas de detalles de dos hornos presentes en el taller de la figura 8

La dimensión más pequeña de cada uno de los hornos es de aproximadamente $25 \mathrm{~cm}$.

a: Horno de fusión, a la izquierda, con el área para operaciones de coladas a la derecha; b: Horno de recocido confeccionado en parte con tejas. 


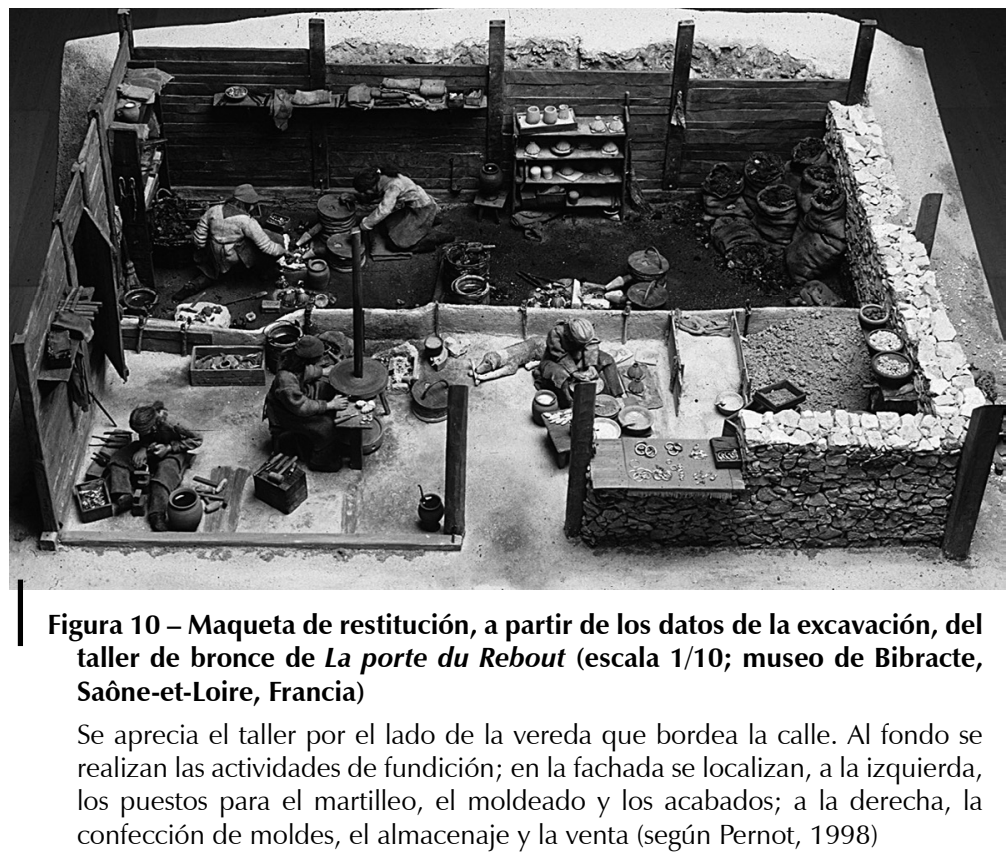

es la siguiente: hacia el lado de la calle, los artesanos martillan, recalientan y acaban; en el lado opuesto, almacenan y preparan las ceras y los moldes; un mostrador de venta se puede haber abierto hacia la calle. El fondo de la pieza se dedica a la fundición; su ubicación, ligeramente excavada, proporciona un sitio protegido del aire y poco iluminado y el suelo es negro como producto al carbón de madera. Esta zona está adaptada a la buena lectura de las temperaturas que acondicionan el éxito de las coladas de metal en los moldes. El espacio de trabajo, de aproximadamente $30 \mathrm{~m}^{2}$, y su partición en función de las etapas de fabricación, invita a proponer una división del trabajo en el taller. Con cada uno de los cuatro puestos ocupado por obreros especializados (moldeado, fundición, martilleo, acabado), la producción en serie puede resultar muy eficiente. En este espacio, cuatro o seis personas, de las cuales una o dos son aprendices a quienes se transmiten los conocimientos, pueden haber producido miles de fíbulas al año.

La reconstrucción del funcionamiento del taller de artesanos de bronce de La porte $d u$ Rebout aporta un elemento importante para la caracterización del «mundo» de los artesanos del metal en esa cultura. El taller, que se localiza en un barrio artesanal, es un pequeño espacio —y no una grán «fabrica»— habilitado en una construcción, parte de la cual era de uso doméstico.

Este nuevo dato aclara el funcionamiento de una sociedad que desarrolla, a gran escala, desde hace solo un siglo, la práctica de una organización urbana. Esta conlleva, más allá de funciones políticas y religiosas, una importante función comercial que incluye una actividad manufacturera de producción de grandes series. Una de las tendencias generales de la sociedad celta en su camino a la 
romanización —el caso preciso del funcionamiento de este taller se ubica entre la conquista de César y las grandes reformas de Augusto- es buscar producir más, más rápidamente y a menor costo, a través de selecciones de aleaciones y procesos de fabricación conformes a este objetivo. Esto se inscribe en la evolución general, observable durante la segunda edad del Hierro en Europa, en la cual los objetos metálicos contribuyen cada vez más, independientemente de su rol de ostentación social, al desarrollo de una economía de consumo de bienes producidos en grandes series. Se trata no solamente de monedas, sino también de herramientas agrícolas de hierro y atuendos de vestir hechos en aleaciones a base de cobre. Como corolario, los presentes datos sobre esa cultura material conllevan, a pesar de la ausencia de textos, a proponer que el estatus de los artesanos, el régimen de tasas de la circulación de las materias primas como de los productos acabados, evolucionan en paralelo a la construcción de una sociedad estatal urbanizada. Finalmente, es muy probable que la innovación técnica -el desarrollo de la utilización del latón, por ejemplo— - se vea estimulada en el marco de una economía de competencia.

\section{Referencias citadas}

ARMBRUSTER, B. \& PERNOT, M., 2006 - La technique du tournage utilisée à l'âge du Bronze final pour la fabrication d'épingles de bronze trouvées en Bourgogne. Bulletin de la Société Préhistorique Française, 103 (2): 1-7.

CHARDRON-PICAULT, P. \& PERNOT, M. (ed.), 1999 - Un quartier antique d'artisanat métallurgique à Autun (Saône-et-Loire) - Le site du Lycée militaire, 320 pp.; París: Documents d'Archéologie Française n. ${ }^{\circ} 76$.

DUBOS, J., 1989 - Le travail du bronze à l'époque gallo-romaine. In: Les bronzes antiques de Paris (P. Velay, ed.): 431-434; París: Musée Carnavalet.

FORMIGLI, E., (ed.), 1999 - I grandi bronzi antichi, 439 pp.; Siena: nuova imagine editrice.

MARYON, H., 1971 - Metalwork \& enamelling, 335 pp.; New York: Dover Publications, Inc.

MONTEIX, N., PERNOT, M. \& COUTELAS, A., 2008 - La metallurgia del piombo fra archeometria ed approcci classici. In: Nuove ricerche archeologiche nell'area vesuviana (scavi 2003-2006). Atti del convegno internazionale, Roma 1-3 febbraio 2007 (P. G. Guzzo \& M. P. Guidobaldi, eds.): 439-447; Roma: L'Erma di Bretschneider. Studi della Soprintendenza Archeologica di Pompei 25.

MOTHES, C. \& PERNOT, M., 2008 - Étude technologique d'un échantillon de mobiliers issus des ateliers de travail des métaux et alliages non ferreux. In: Rennes antique (D. Pouille, ed.): 395-415; Rennes: Presses Universitaires de Rennes.

PERNOT, M., 1993 - Approche de l'artisanat du «bronze» au Mont-Beuvray. La fabrication de fibules et l'organisation d'un atelier. Revue d'archéométrie, 17: 41-50.

PERNOT, M., 1998 - Des ateliers métallurgiques près de la porte du Rebout. In: L'oppidum de Bibracte. Un bilan de onze années de recherche (1984-1995) (K. Gruel \& D. Vitali, eds.): 52-60. Gallia, 55. 
PERNOT, M., 1999 - La métallographie. In: À la recherche du métal perdu - Les nouvelles technologies dans la restauration des métaux archéologiques: 65-67; París: Musée archéologique du Val d'Oise, Éditions Errance.

PERNOT, M., 2000 - Forming bronze by plastic deformation around the $1^{\text {st }}$ millennium BC in Western Europe. In: Thermomechanical Processing of Steel - J.J. Jonas Symposium (S.Yue \& E. Essadiqi, eds.): 615-626; Montreal: The Conference of Metallurgists COM 2000, Ottawa, 20-23 august 2000, Metallurgical Society of the Canadian Institute of Mining, Metallurgy and Petroleum.

PERNOT, M., 2003 - Étude technique de quelques objets en bronze. In: Rolley, vol. 1: 265-277; vol. 2: pl. 24.

PERNOT, M., SIREIX, C. \& ADAMSKI, F., 2007 - Première étude archéométrique des vestiges de l'atelier gallo-romain de production de grands bronzes du Grand Hôtel de Bordeaux. In: La mesure du passé : contributions à la recherche en archéométrie (2000-2006) (A. Bain, J. Chabot \& M. Mousette, eds.): 119-127; Oxford: BAR International Series 1700 .

PININGRE, J.-F., 2002 - Le dépôt d'Évans (Jura, France) et les dépôts de vaisselle métallique de l'âge du Bronze final en France. Archäologisches Korrespondenzblatt, 32: 59-66.

ROLLEY, C., 1983 - Les bronzes grecs, 270 pp.; Fribourg (Suisse): Office du Livre.

ROLLEY, C. (ed.), 2003 - La tombe princière de Vix, vol. 1, 383 pp.; vol. 2, 135 pl.; París: Picard.

TOLEDO I MUR, A. \& PERNOT, M. (ed.), 2008 - Un atelier monétaire gaulois près de Poitiers : Les Rochereaux à Migné-Auxances (Vienne). Gallia, 65: 231-272. 